\title{
Motivações para a formação de redes de colaboração em bancas examinadoras de defesas de mestrado e doutorado
}

\author{
Motivations for the formation of collaborative networks in master's and doctoral's committees
}

Kelma Patrícia de Souza

Doutoranda em Geografia pela Universidade Federal de Uberlândia, Brasil. Bibliotecária no Sistema de Bibliotecas da Universidade Federal de Uberlândia, Brasil. https://orcid.org/0000-0002-8112-9871

E-mail: kelma.biblio@gmail.com

João de Melo Maricato
Doutor em Ciência da Informação pela Universidade de São Paulo - USP, Brasil.
Professor do Programa de Pós-graduação em Ciência da Informação da Universidade de Brasília - UnB, Brasil.
$\frac{\text { https://orcid.org/0000-0001-9162-6866 }}{\text { E-mail: jmmaricato@ @mail.com }}$

\section{Resumo}

A formação de bancas examinadoras para avaliar dissertações e teses é um requisito do processo de titulação de mestres e doutores no Brasil. Esse processo, por sua vez, tem dentre suas características motivações objetivas e subjetivas, requerendo tempo e dedicação de orientandos, orientadores e membros avaliadores. Diante disso, o objetivo desta pesquisa foi investigar fatores influenciadores dos processos de escolha desses componentes motivacionais. Para isso, estudaram-se as dinâmicas de colaboração e organização de redes dos membros dessas comissões em trabalhos submetidos ao Programa de Pós-Graduação em Geografia da Universidade Federal de Uberlândia, entre 2000 e 2018. Nesse sentido, o presente estudo tem natureza exploratória documental via coleta de trabalhos acadêmicos, página eletrônica do Repositório Institucional e dados acadêmicos de docentes registrados na Plataforma Lattes, do Conselho Nacional de Desenvolvimento Científico e Tecnológico. A partir desses levantamentos, foram produzidos quadros, tabelas, gráficos e grafos que subsidiaram as referidas análises. Como resultado, constatou-se que a rede de colaboração em questão é baseada em vínculos originados pela formação acadêmica na área da Geografia e composta por docentes e/ou pesquisadores de universidades localizadas no estado de Minas Gerais, com destaque para a influência estadual e regional. Observou-se, por fim, que os convites para composição de bancas não são motivados pelas relações estabelecidas entre orientadores e examinadores durante sua formação acadêmica.

Palavras-chave: Cientometria. Examinadores. Programa de Pós-Graduação. Dissertações e teses. Redes de colaboração.

\begin{abstract}
The formation of examining boards to evaluate dissertations and theses is a requirement for the process of obtaining masters and doctoral degrees in Brazil. This process, in turn, has among its characteristics objective and subjective motivations, requiring time and dedication from advisees, advisors and evaluator members. Therefore, the objective of this research was to investigate influencing factors in the processes of choosing these motivational components. For this, the dynamics of collaboration and organization of networks of the members of these commissions in works submitted to the Graduate Program in Geography at the Federal University of Uberlândia between 2000 and 2018 were studied. This study has an exploratory documentary nature via the collection of academic papers, the Institutional Repository website and academic data from professors registered in the Lattes Platform, of the National Council for Scientific and Technological Development. From these surveys, charts, tables, graphs and graphs were produced that supported the referred analyses. As a result, it was found that the collaboration network in question is based on links originated by academic training in the area of Geography and composed of professors and/or researchers from universities located in the state of Minas Gerais, with emphasis on the state and regional influence. Finally, it was observed that the invitations to compose panels are not motivated by the relationships established between advisors and examiners during their academic training.
\end{abstract}

Keywords: Scientometry. Examiners. Graduate Programs. Dissertations and theses. Collaboration networks.

InCID: R. Ci. Inf. e Doc., Ribeirão Preto, v. 12, n. 2, p. 173-193, set. 2021./fev. 2022.

DOI: 10.11606/issn.2178-2075.v12i2p173-193 


\section{Introdução}

de mestrado e doutorado

A presente pesquisa busca refletir sobre hipóteses norteadoras da formação de bancas examinadoras de mestrado e doutorado, as redes de colaboração estabelecidas por parcerias entre orientadores e demais examinadores, bem como redes de colaboração interinstitucionais oriundas das afiliações dos docentes envolvidos. A denominação de redes para estudar os fenômenos elencados é fundamentada por Costa et al. (2003), que atribuem o seu surgimento ao instante no qual um grupo identifica entre si uma “capacidade de projeto comum”. Portanto, entende-se que as bancas em questão possam ser consideradas um tipo de rede social colaborativa.

Para as análises, adotaram-se princípios dos Estudos Métricos da Informação (EMI), assim como de análise de redes sociais e colaborativas. Tal escolha se apoia no fato de esses conceitos proporcionarem subsídios teórico-metodológicos em avaliações de produções acadêmicas por parte de pesquisadores, comissões e instituições (OLIVEIRA, 2018). Os indicadores gerados são relacionados aos indicadores de ligação — inseridos em casos nos quais a coocorrência de autoria, ou de citações, ou de palavras, dentre outras ligações, tem o intuito de mapear e elaborar redes de colaboração científica (OLIVEIRA, 2018).

Com isso, este estudo possui caráter qualiquantitativo de natureza exploratória, utilizando-se dos métodos e técnicas dos EMI, especificamente no que se refere à cientometria e indicadores de ligação, aplicados aos membros participantes das bancas examinadoras e suas variáveis. Mantém-se aqui a relação com a cientometria, por permitir a produção e análise de um conjunto de indicadores, bem como o estudo de aspectos quantitativos da ciência e suas atividades como disciplina seguimento da Sociologia da Ciência (MACIAS-CHAPULA, 1998).

A participação de pesquisadores em processos de bancas enquanto examinadores, tanto em sua própria instituição de vínculo quanto em outras, é um dos quesitos determinados pela Coordenação de Aperfeiçoamento de Pessoal de Nível Superior (Capes) ${ }^{1}$ (BRASIL, 2016) para a titulação de mestres e doutores no Brasil. Além de conferir crédito às universidades, essa atividade possibilita conhecer pesquisas concluídas ou em andamento, temáticas abordadas nos cursos de pós-graduação, bem como o fortalecimento de áreas via troca de conhecimentos (TELMO, 2019).

\footnotetext{
${ }^{1}$ Órgão que supervisiona e avalia as instituições de ensino superior e seus programas (BRASIL, 2017).
} 
Sua composição é uma prática comum em diversos países, havendo particularidades tanto em contexto nacional quanto internacional. A variação de seu formato pode ocorrer, por exemplo, conforme o grau de titulação do orientando, normas de cada programa ou instituição de ensino, quantidade de membros em cada comissão, grau mínimo de qualificação/formação e atuação profissional e institucional. Se necessário, essa organização pode sofrer modificações quando houver necessidade de o examinador titular ser substituído por um suplente.

O exame final, para outorga dos títulos de mestre e doutor, é oriundo da Idade Média, período no qual o candidato realizava uma antítese, ou seja, defendia sua tese às opiniões contrárias ou contestações de seus avaliadores (SALOMON, 2014). Por sua vez, o formato oral é mantido até os dias atuais, apesar de haver algumas distinções nas exigências de apresentação dos documentos finais, em função das demandas e especificidades de cada curso, universidade, programa de pós-graduação e/ou país. Mesmo com essas peculiaridades, conforme Brasil (2017), a qualificação de doutorado somente pode ser atribuída mediante defesa direta de tese.

Além de aspectos objetivos, normatizados pelas instituições, a constituição das bancas conta com dinâmicas subjetivas, que podem ser avaliadas empiricamente por intermédio da análise de redes sociais. Diante da composição de orientador e seus pares nessas comissões, a pergunta norteadora desta pesquisa é: como são estruturadas tais dinâmicas e redes de colaboração em um programa de pós-graduação? Para respondê-la, selecionou-se como unidade de estudo o Programa de Pós-Graduação em Geografia da Universidade Federal de Uberlândia (PPGeo/UFU), cuja abrangência possui cursos de metrado e doutorado na referida área.

Partindo-se dessa questão geral, foram consideradas as seguintes questões específicas quanto à formação da rede colaborativa das bancas examinadoras: a composição resulta da relação baseada em temáticas decorrentes da carreira acadêmica dos orientadores e membros convidados? Advém de associações estabelecidas durante a trajetória acadêmica dos orientadores e examinadores, tais como contato entre orientadores e orientandos ou vínculos com colegas de turma, ou seja, existem parcerias interinstitucionais que se estabelecem durante a formação ou em decorrência da relação orientador/orientado? A colaboração em bancas examinadoras é fortalecida em decorrência da proximidade geográfica dos seus membros?

Para responder essas perguntas, investigou-se como se formou a rede de colaboração dos membros das bancas examinadoras de defesa de mestrado e doutorado submetidas ao PPGeo/UFU. Nesse sentido, determinaram-se os seguintes objetos de estudo: as dissertações e 
teses defendidas no PPGeo/UFU disponíveis no Repositório Institucional da UFU² (RI/UFU) entre os anos 2000 e 2018; os respectivos membros das bancas examinadoras; os currículos dos docentes envolvidos em tais processos, publicados na plataforma Lattes $^{3}$ do Conselho Nacional de Desenvolvimento Científico e Tecnológico ( $\mathrm{CNPq})$; as dissertações e teses defendidas por estes, localizadas em buscas na web.

\section{Constituição de redes de colaboração em bancas examinadoras}

O estímulo para o desenvolvimento deste trabalho partiu da necessidade de se observar fatores, dinâmicas e motivações para a seleção de examinadores de mestrado e doutorado de maneira ampla no âmbito do PPGeo/UFU, a fim de se compreender como suas bancas de defesa são constituídas. Para tanto, esta seção aborda parte da literatura relativa às relações entre orientandos, orientadores e examinadores, assim como os principais elementos influenciadores da composição dessas comissões avaliativas.

No Brasil, de maneira geral, os orientadores são responsáveis por definir os demais examinadores, internos e externos, que irão participar do processo avaliativo. No caso do PPGeo/UFU, tais regras estão descritas em seu primeiro regulamento, aprovado em 2003. Já em 2016, foi criada a Instrução Normativa PPGeo/UFU nº 01/2016, para estabelecer os critérios e procedimentos a serem adotados nessas bancas. A estruturação desse documento objetivou a isenção no julgamento dos trabalhos, sendo mantidas suas diretrizes iniciais. Dentre outros aspectos constantes na normativa, destacam-se:

Art. $1 . \S 2^{\circ}$ - Serão aprovadas no máximo 3 (três) participações anuais de membros externos de bancas de doutorado ou de mestrado no Programa.

Art. 2. $\S 2^{\circ}$ - I) A banca de avaliação de dissertação de MESTRADO deverá ser composta por 3 (três) membros sendo: 1 Orientador/Presidente +1 interno +1 externo.

II) A banca de avaliação de tese de DOUTORADO deverá ser composta por 5 (cinco) sendo: 1 Orientador/Presidente +2 internos +2 externos.

III) Não deverá ser indicado para compor a banca de mestrado ou de doutorado mais de 1 (um) membro componente que tenha sido titulado pelo mesmo orientador/presidente da comissão (UNIVERSIDADE FEDERAL DE UBERLÂNDIA, 2016, p. 2).

Em 2018, aprovou-se o regulamento do PPGeo/UFU, ainda em vigor, no qual as regras determinadas anteriormente também foram preservadas. É importante destacar que no conjunto

\footnotetext{
2 Após a aprovação de examinadores, as dissertações e teses são submetidas ao RI/UFU. Cf. http://repositorio.ufu.br/

${ }^{3}$ Cf. http://lattes.cnpq.br/
} 
de dados analisados e respectivos resultados deve constar tanto as normativas da UFU quanto do programa.

Nesse sentido, Telmo (2019) aponta questões relevantes em uma perspectiva social e colaborativa que qualificam a formação de bancas. Conforme a autora, as relações interinstitucionais surgem como oportunidade para a construção de novos pesquisadores e aprimoramento de abordagens de estudos defendidos, devido a outros pareceres. A estudiosa ainda destaca o fato de recursos tecnológicos serem uma maneira de aproximar componentes externos, em casos de distância geográfica, quando fatores financeiros podem impedir a participação presencial nesse contexto. Diante dessa afirmação, é possível depreender que a proximidade territorial entre os membros pode favorecer esse tipo de colaboração.

Balancieri (2004) evidencia que o vínculo entre orientador e orientando pode nascer mediante a necessidade de publicações científicas. Porém, essa associação, hipoteticamente, pode se fortalecer ao longo do tempo, originando outras formas de colaboração pressuposto investigado nesta pesquisa. Ou seja, pretende-se investigar se a colaboração indicada por Balancieri evolui para a colaboração oriunda da participação em bancas.

De acordo com Tinkler e Jackson (2004), o diálogo entre orientadores e orientados quanto à escolha dos membros de banca é relevante em diversos aspectos, tais como: identificar se existem conexões acadêmicas, pessoais ou financeiras; verificar se há algum conflito pessoal ou acadêmico; avaliar se a temática abordada é compatível com os potenciais participantes; saber qual a preferência do autor em discutir seu trabalho; encontrar um futuro patrocinador apropriado para esse último; por fim, conhecer detalhadamente a pesquisa para selecionar os examinadores adequados. Portanto, a escolha pode ser pautada no consenso e proporcionar maior segurança ao orientando.

Um grupo expressivo de trabalhos confere mais ênfase para os aspectos técnicos e objetivos que regem essa seleção. Tinkler e Jackson (2000) destacam três critérios para essa escolha: credenciais acadêmicas, experiência ou qualificação e independência. Nesse caso, as duas primeiras são direcionadas pela afinidade temática dentre os envolvidos. Em outro estudo, os autores (TINKLER; JACKSON, 2004) destacam algumas maneiras de se definir um examinador adequado, tais como: análise de trabalhos publicados; revisões feitas sobre outras pesquisas; condução de apresentação em uma conferência; estilos de respostas e perguntas, incluindo seu teor, nesses eventos; renome como membro de banca; tipo e padrão de bancas das quais participou; vínculos pessoais ou acadêmicos com orientandos. 
Na mesma linha, Kiley (2009) cita, em um estudo sobre esse processo em instituições australianas, cinco aspectos geralmente considerados por orientadores a respeito desse tipo de definição: alinhamento sobre temática e metodologia; entendimento da maneira com que um trabalho foi desenvolvido; disponibilidade; experiência recente na academia; participação em bancas anteriores. No mesmo ano, Pezzi e Steil (2009) observaram em uma de suas pesquisas que esse último fator tem sido determinante em processos similares. Por sua vez, em estudos de Tinkler e Jackson (2000) e Kiley (2009), a experiência e o domínio do examinador sobre a temática a ser abordada na defesa das dissertações e teses são requisitos primordiais.

A maioria dos trabalhos, a exemplo daqueles destacados nos parágrafos anteriores, parte de uma perspectiva teórica, independentemente de haver traços mais ou menos subjetivos. Diante disso, a presente pesquisa explorou alguns desses elementos, porém de maneira empírica, por meio da análise de redes. Para compreender aspectos sociais de formação de bancas avaliadoras, é relevante trazer à tona o conceito de rede e realizar algumas aproximações em relação ao que se entende por colaboração. Conforme essa perspectiva, investigou-se a hipótese de a escolha dos membros das bancas estar relacionada com a temática de pesquisa do membro convidado, a partir de sua titulação em nível de graduação, mestrado e doutorado.

Em virtude disso, convém destacar que uma rede é composta por nós (atores), vínculos (relações) e fluxos. Segundo Dias (2000), ela viabiliza duas estratégias: circular e comunicar, através das quais os fluxos implicam a sua existência cuja propriedade inicial aqui é de conectar, sendo os nós os lugares de conexões, a referência.

De maneira análoga, pode-se aplicar definições de rede ao objeto a ser analisado no presente trabalho. Com isso, é possível verificar se a formação das bancas tem atendido aos aspectos objetivos - a exemplo da especialidade do membro convidado na temática - e subjetivos - a exemplo de relações afetivas estabelecidas entre orientador e orientando. Assim, os orientadores podem ser considerados os nós, ao assumirem a função de conectores; as bancas são os vínculos; os orientandos e seus trabalhos são os fluxos responsáveis por fazer uma pesquisa circular. Essas inter-relações, juntamente com os examinadores, tecem as redes colaborativas de bancas de defesa de mestrado e doutorado do PPGeo/UFU.

O vínculo constituído entre os examinadores envolvidos nesses processos é aqui denominado de rede de colaboração entre membros de bancas examinadoras. Conforme Telmo (2019), o campo científico deriva não somente da produção de trabalhos em coautoria, mas também quando ocorre outras maneiras de participação e contribuição. Nesse sentido, a autora 
enfatiza a motivação de uma rede social colaborativa, permeada por socialização de informações. Da mesma maneira, Balancieri (2004) destaca a existência de uma grande variedade de associações, sendo as parcerias especializadas motivações óbvias para o alcance dos objetivos de pesquisa, assim como a proximidade com outros pesquisadores para agregar conhecimento.

A rede de colaboração engendrada por esses avaliadores, consequentemente, apresenta uma diversidade de possibilidades de análises relacionadas com a afiliação dos demais membros de bancas. Partindo desse princípio, pode-se constatar a existência de rede de colaboração intrainstitucional e interinstitucional, desenvolvidas, respectivamente, pelas relações construídas dentro de uma universidade (no presente caso, a UFU) e pelas parcerias com examinadores externos. Além disso, esse tipo de contato é composto por docentes de outros países, que, conforme Telmo (2019), estreitam laços acadêmicos e de produção científica, bem como fomentam a internacionalização de um programa.

Estudos dessas redes colaborativas, conforme Danuello e Oliveira (2012), têm a capacidade de ressaltar as relações entre os atores envolvidos e, dessa forma, retratar, descrever e representar a estrutura de um grupo. Essa última, por sua vez, pode ser estudada, como destacado, sob o ponto de vista intrainstitucional ou interinstitucional. Notadamente, pesquisas com esse enfoque no geral se utilizam de métodos cientométricos, com o propósito de analisar a colaboração entre autores, instituições, países, dentre outras possibilidades. Logo, tal avaliação pode ser enquadrada no conjunto de estudos que tem a ciência e suas dinâmicas como ponto de interesse. As motivações, dinâmicas e fatores influenciadores da formação dessas redes de colaboração em bancas são a essência deste estudo. 


\section{Metodologia e procedimentos metodológicos}

Este trabalho tem característica qualiquantitiva, com natureza exploratória, subsidiada por levantamento bibliográfico pertinente à temática. Baseia-se nos princípios da cientometria, enquanto método que estuda a atividade científica, aplicada às dissertações e teses, produtos das instituições de ensino e pesquisa. Para mapeamento de uma rede, convém destacar a análise de coocorrência e indicadores de ligação, típicos da cientometria.

Após busca no RI/UFU, observou-se que o trabalho mais antigo defendido no PPGeo/UFU é de 2000, dessa forma, a pesquisa teve recorte temporal entre os anos de 2000 e 2018. Utilizou-se a página do programa ${ }^{4}$ como fonte de consulta de informações internas, como normas gerais, corpo docente permanente, histórico e características. A pesquisa considerou o total de 473 documentos, sendo 311 dissertações e 162 teses.

Os dados extraídos foram registrados em planilhas da ferramenta Excel. Por sua vez, a investigação sobre os orientadores contemplou coleta e análise das informações a seguir apuradas nos trabalhos acadêmicos: docente orientador, membros de bancas e suas afiliações. Em coleta na plataforma Lattes,${ }^{5}$ foi observada a presença de ata de defesa ou folha de aprovação para apuração de informações complementares através de dados de afiliação e trabalhos localizados na web, quantificados por ano e nível.

Ainda se utilizou da plataforma para captar: endereço de currículos; formação acadêmica (graduação, mestrado e/ou doutorado); instituição formadora e ano de conclusão de curso. Durante o processo, em situações nas quais o pesquisador tivesse mais de uma graduação, foi considerada a mais recente; e, em casos de pós-graduação, levou-se em conta a formação em Geografia. Além disso, obtiveram-se na internet informações sobre a formação de bancas em que os orientadores e examinadores foram participantes, tais como: identificação, formações acadêmicas e instituições de vinculação.

Para identificar conexão entre os orientadores da UFU (total de 36) e membros das bancas (1.273), avaliaram-se as coocorrências de afiliação institucional, localização geográfica e instituição de formação nos níveis de graduação, mestrado e doutorado. Ainda, para analisar o vínculo entre os envolvidos, foi atribuída a nomenclatura "núcleo formador" aos docentes que

\footnotetext{
${ }^{4}$ Cf. http://www.ppgeo.ig.ufu.br/

${ }^{5}$ A Plataforma Lattes reúne, dentre outros, detalhadamente milhares de currículos de profissionais, estudantes, professores, pesquisadores e cientistas brasileiros.
} 
orientaram ou participaram de bancas de defesas de mestrado e/ou doutorado dos orientadores dos trabalhos defendidos no PPGeo/UFU ou dos examinadores envolvidos.

O software Gephi ${ }^{6}$ foi utilizado para construção e representação das matrizes dos grafos $^{7}$, visualização gráfica, bem como análise das coocorrências e redes de colaboração dos avaliadores e seus atributos. Por meio dessa ferramenta, aplicaram-se os algoritmos Force Atlas para gerar o "Grafo 1 - Rede de colaboração entre membros de bancas examinadoras", e o Fruchterman Reingold ${ }^{8}$ para construção do "Grafo 2 - Rede de colaboração interinstitucional formada pelo PPGeo/UFU".

\section{Visão geral das redes de colaboração estabelecidas entre os membros do PPGeo/UFU}

Nos objetos pesquisados, foram identificados 36 orientadores, que realizaram 473 orientações, sendo 311 de mestrado e 162 de doutorado. Considerando-se todas as bancas, constata-se a existência de 1.273 parcerias, das quais 633 se deram com membros internos (colaboração intrainstitucional) e 636, com membros externos (colaboração interinstitucional). É importante observar que foi feita a busca por afiliações de membros de bancas de 208 trabalhos por meio de currículos disponíveis na Plataforma Lattes, pois essa informação não constava nas folhas de aprovação e/ou atas de defesas. Também não foi possível identificar o currículo de 5 docentes; enquanto 3 trabalhos não possuíam a identificação dos membros de banca. A Tabela 1 apresenta uma breve descrição a respeito dos 36 orientadores, em ordem alfabética, acompanhada de um resumo de informações de defesas conduzidas.

Observa-se que a docente vinculada ao PPGeo/UFU que mais concluiu orientações no período foi Beatriz Ribeiro Soares, 37 no total. Ela ainda possui o maior número de parcerias (116), sendo 59 delas interinstitucionais e 56 intrainstitucionais. O volume de 52 parceiros em 37 bancas representa em média 1,4 parceiro por orientação, indicando concentração de bancas com pouca colaboração. A considerável média de 3,1 parcerias em relação às orientações é consequência das bancas de doutorado, pois em cada banca de mestrado são convidados 2 parceiros. Destaca-se o fato de a docente não ter constado de modo repetido em nem uma banca.

\footnotetext{
${ }^{6}$ Software para análise de dados de redes. Ver: https://gephi.org/

${ }^{7}$ De acordo com Balancieri (2004), um grafo é representado matematicamente por conjuntos individuais de vértices e arestas. Os primeiros são exibidos através de pequenos círculos, enquanto as segundas aparecem em formato de retas ou curvas, com o intuito de simbolizar a relação entre objetos.

${ }^{8}$ Tem a função de centralizar os nós com mais links.
} 
Tabela 1 - Caracterização dos 36 orientadores e suas bancas no PPGeo/UFU (2000-2018)

\begin{tabular}{|c|c|c|c|c|c|c|c|c|c|c|c|c|c|c|c|c|c|}
\hline \multirow{2}{*}{\multicolumn{2}{|c|}{ Orientador }} & \multirow[b]{2}{*}{$\begin{array}{l}\text { Ories } \\
\text { aphies }\end{array}$} & \multirow[b]{2}{*}{ Perivido } & \multicolumn{2}{|c|}{ Ninel } & \multirow[b]{2}{*}{$\begin{array}{l}\text { Parce- } \\
\text { rias }\end{array}$} & \multirow{2}{*}{$\begin{array}{c}\text { Médin } \\
\text { Ue parce } \\
\text { rias por } \\
\text { orients } \\
\text { çst }\end{array}$} & \multirow{2}{*}{$\begin{array}{l}\text { Parcei: } \\
\operatorname{ros}^{(2)}\end{array}$} & \multirow{2}{*}{$\begin{array}{c}\text { Media } \\
\text { de } \\
\text { parcei- } \\
\text { ros por } \\
\text { vrien. } \\
\text { tacio }\end{array}$} & \multicolumn{3}{|c|}{$\begin{array}{l}\text { Affiliacries } \\
\text { Instirucionais }\end{array}$} & \multicolumn{4}{|c|}{ Maioves parcerias } & \multirow{2}{*}{$\begin{array}{c}\text { Repericilo } \\
\text { de } \\
\text { baeca }\end{array}$} \\
\hline & & & & $\begin{array}{l}\text { Mes- } \\
\text { trado }\end{array}$ & $\begin{array}{l}\text { Douto- } \\
\text { rado }\end{array}$ & & & & & Intra & Inter & ST* & Evaninabor Interno & $\begin{array}{l}\text { Partiel- } \\
\text { paçós }\end{array}$ & Examiador externo & $\begin{array}{l}\text { Partici } \\
\text { pactes: }\end{array}$ & \\
\hline 1 & Adriary A.MI & 17 & 20162015 & 15 & 2 & 39 & 23 & 26 & L.4 & 19 & 20 & 9 & Ronselvalit I. Santos & 4 & Toḡe D. Lma & 4 & Näe \\
\hline 2 & Antorsio G Sibetro & 2 & $2003-2004$ & 2 & 0 & 4 & 2,0 & 4 & 2,0 & 2 & 2 & p & $\begin{array}{l}\text { C7andate A. D } \\
\text { Bactaro: }\end{array}$ & 1 & Atntlento Feltras Filho & 1 & Nio \\
\hline 3 & Beatrit R Soares & 37 & $2005-2013$ & 17 & 20 & 116 & 3,1 & 52 & 1,4 & 56 & 59 & 1 & Willien R. Ferrein & 10 & $\begin{array}{l}\text { Celene C.M. A. } \\
\text { Bamern; Edarda M. } \\
\text { Costz }\end{array}$ & 5 & $\mathrm{Nz}$ o \\
\hline 4 & Cadles R. Arandio & 14 & 2007.2013 & 9 & 5 & 38 & 27 & 20 & 14 & 19 & 19 & 0 & Marcele C. Chelots & 5 & Leopoldo G. Thiesen & 4 & NLO \\
\hline 5 & $\begin{array}{l}\text { Clanudete A.D } \\
\text { Baccaro }\end{array}$ & 1 & 3001 & 1 & 6 & 2 & 2,0 & 2 & 2,0 & 1 & 1 & 8 & Suely R. Grossi & 1 & Antonio J. T. Ouem & 1 & $\mathrm{~N} \mathrm{~N}_{0}$ \\
\hline 6 & Dersise L. Fenteira & 3 & $2005-2010$ & 5 & 9 & 10 & 20 & 7 & 1,4 & 5 & 5 & 0 & \begin{tabular}{|l|} 
William R. Fetreira, \\
Deatrin R Soares
\end{tabular} & 2 & Archimedes $A$ Rais of & 2 & N3is \\
\hline 7 & Douglas G. Santos & 2 & $2011-2013$ & 1 & 1 & 6 & 3,0 & 5 & 2,5 & 3 & 3 & 0 & - & 1 & Katia Mazpa & 2 & Nas \\
\hline 8 & Geisa D. G. Cleps & 11 & $2011-2015$ & 9 & 2 & 27. & 25 & 17 & 1.5 & 14 & 13 & 0 & Williem R. Fereira & 4 & Lenissa G.M. Abrdo & 3 & $\operatorname{Sim}(1)$ \\
\hline 9 & $\begin{array}{l}\text { Gelse S S. C: } \\
\text { Rodriguses }\end{array}$ & 3 & $2017-2015$ & 3 & 10 & 6 & 2,0 & 6 & 20 & 3 & ; & e & - & 1 & - & 1 & Nise \\
\hline 10 & Jolo Cleps Sanior & 26 & $2005-2016$ & 19 & 9 & 67 & 2.6 & 35 & 13 & 33 & 34 & 0 & Vera L.S. Pessda & 9 & Luciene Rosrigues & 4 & $\sin (1)$ \\
\hline 11 & Jorse L. 5. Brito & 17 & 2004.2017 & II & 6 & 65 & 2,6 & 51 & 1.3 & 24 & 20 & 1 & Robento Rlosa & 5 & Jolo D Lima & 4 & N3io \\
\hline 12 & Júfo C.I. Ramires & 17 & $2005-2018$ & 9 & 3 & 50 & 2,9 & 28 & 1.6 & 25 & 25 & 0 & Beatrir R. Soures & 6 & Mzgda V. Sdrua & 4 & $\mathrm{~N} 3 \mathrm{O}$ \\
\hline 13 & Tuit A Ofrvein & 2 & 2017.2018 & 2 & 0 & 4 & 2,0 & 3 & 13 & 2 & 2 & 0 & $\begin{array}{l}\text { Vanderlei } 0 . \\
\text { Feneira }\end{array}$ & 2 & . & t & $\mathrm{Nz} 0$ \\
\hline 14 & Luit Nishiyama & 21 & $2000-2015$ & 13 & s & $3 t$ & 2,8 & 36 & 1,7 & 28 & 29 & 1 & Vania S. Rosolen & 7. & $\begin{array}{l}\text { Angela M. Soutes: } \\
\text { Suely R. D. Crossi }\end{array}$ & 4 & Nis \\
\hline 15 & Marded Fele & 17 & $2003-2015$ & 10 & 7 & 29 & 2.9 & 33 & 1.9 & 24 & 24 & 1 & $\begin{array}{l}\text { Madene I. M } \\
\text { Colesenti }\end{array}$ & 5 & Suely R Grossi & 4 & Nio \\
\hline 16 & Marcelo C. Chelothi & 7 & $2014-2018$ & 7 & 0 & 14 & 20 & 9 & 1,3 & 7 & ? & 0 & Jolo Cleps Jt & 4 & Munto M. O. Saura & 2 & N2o \\
\hline 17 & Mana B, J. Bemardes & 1 & 2013 & 1 & 0 & 2 & 2,0 & 2 & 20 & 1 & 1 & 0 & $\begin{array}{l}\text { Matlene T. MA } \\
\text { Colesanti }\end{array}$ & 1 & Patricis F. Mates & 1 & $\mathrm{NBO}$ \\
\hline 18 & $\begin{array}{l}\text { Marbene I.M. } \\
\text { Colesunti }\end{array}$ & 28 & 2003 -2013 & 15 & 13 & 9 & 2,8 & 45 & 10 & $\neq 0$ & 39 & e & $\begin{array}{l}\text { Maria Beatrix I } \\
\text { Bemendes } \\
\end{array}$ & 8 & Vateria G F. Nekms & 9 & $\sin (3)$ \\
\hline 19 & Mentei E. Q. Pereira & 6. & $2014-2011$ & 6 & 0 & 52 & 2,0 & 11 & 11 & 4 & 9 & 0 & - & 1 & Marcos K. Manushima & 2 & N20 \\
\hline 20 & Paslo C. Menders & 9 & 2013.2015 & 9 & 0 & 19 & 2.1 & 12 & 13 & 11 & 8 & 0 & SamuelC Lims & 4 & Joino D Lima & 3 & $\sin (1)$ \\
\hline 21 & Paulo 1. B. Femandes & 1 & 2018 & 0 & 1 & 3 & 3,0 & 3 & 3,0 & 2 & 1 & 0 & Beatrix R. Soures & 1 & Mauro G. Mendonça & 1 & N2o \\
\hline 22 & Ruta C. M. Souta & 10 & 2011.2017 & 9 & 1 & 22 & 22 & 13 & 1,3 & 9 & $B$ & 0 & Oláucia C. Oonnes & 5 & Paslo R. A. Bomfim & 4 & N30 \\
\hline 23 & Robetto Rosa & 18 & $2006-1013$ & in & 8 & 50 & 28 & 20 & 1.1 & 24 & 26 & 0 & Jarge L S Brito & 9 & EdsonE Sano & 7 & $\sin (1)$ \\
\hline 24 & Rosselvelt J.5antos & 28 & 2006.2017 & 15 & 13 & 87 & 3,1 & 48 & 117 & 42 & 45 & 0 & Beatrit R. Soures & 6 & Marts G. de Alneida & 3 & $N 30$ \\
\hline 25 & Samuel C. Lima & 33 & 2003-2017 & 19 & 14 & 95 & 2,9 & 97 & 1.7 & 46 & 48 & 1 & Júbo C. L Ramires & 9 & Raul B. Guinaràes & 7 & $\mathrm{~N} 20$ \\
\hline 26 & Selve C. Roctigues & 30 & $2006-2013$ & is & 12 & 79 & 2,6 & 46 & 1,9 & 70 & 30 & 0 & Anatcenio S. Pedrosa & 6 & $\begin{array}{l}\text { Antonio T. Guens; } \\
\text { Cristina H. R. R. } \\
\text { Auguarion }\end{array}$ & 4 & $\sin (1)$ \\
\hline 27 & Suely. R. D. Grossi & 1 & 2001 & 1 & 0 & 2 & 2,0 & 2 & 20 & 1 & 1 & 0 & Antonio G. Ribeiro & 1 & Celene C. M. A. Barnsira & 1 & $\mathrm{Nz}$ \\
\hline 28 & Tǘto Barbosa & 4 & $2016-2013$ & 4 & 6 & 8 & 20 & 7 & 13 & 5 & 3 & 0 & - & 1 & Clson C. Fagieni & 2 & $\mathrm{Nag}$ \\
\hline 29 & Vandetlet O. Ferrina & 6 & $2015-2017$ & 16 & 0 & 14 & 2,3 & 11 & 111 & 7 & ? & 6 & Angela M Soarts & 2 & $\begin{array}{l}\text { Fulvie Cupolillo: } \\
\text { Roberto Rosa }\end{array}$ & 2 & Nis \\
\hline 30 & Vania R F. Vlach & 24 & $2003-2014$ & 15 & 9 & 68 & 28 & 39 & 1.6 & 36 & 32 & 0 & Jübo C. L Ramirts & 5 & Marisia M. S. Buitoni & 5 & $\mathrm{~N} 20$ \\
\hline 31 & Varmin S. Rosolen & 7 & 20123016 & 6 & 1 & 16 & 23 & 13 & 1.9 & 3 & 8 & 0 & Fhas N. Borget & 2 & Gullherme T Bueno & 2 & $\mathrm{Na}$ \\
\hline 32 & Vera L S. Pessòa & 9 & $2005-2011$ & 4 & 5 & 28 & 3,1 & 15 & 1,7 & 14 & 14 & 6 & Deatrin R. Soures & 6 & \begin{tabular}{|l|} 
Estevane P. P. Mendes; \\
Gtaucio I. Marafon; \\
Helena A. Mesquita; \\
Marcelo R. Mendonça \\
\end{tabular} & 2 & $\mathrm{~N} 3 \mathrm{o}$ \\
\hline 33 & Vicente P. Silve & 14 & $2011-2013$ & 9 & 5 & 37 & 2,6 & 29 & 2,1 & 19 & is & 9 & \begin{tabular}{|l|} 
Gelze S.S.C. \\
Rodnigues; Marceto \\
C. Cheloti
\end{tabular} & 5 & Renato L. M. Léds & 2 & $\operatorname{sim}(1)$ \\
\hline 34 & Vitor Rubeiro Fitho & 15 & $2009-2018$ & 10 & 5 & 39 & 2,6 & 23 & 1,3 & 19 & 20 & 0 & Beatnir R. Soures & 10 & $\begin{array}{l}\text { Femando L. Arsujo } \\
\text { Soltenho; Gerabso A. } \\
\text { Soura }\end{array}$ & 3 & $\sin (1)$ \\
\hline 35 & $\begin{array}{l}\text { Washington L } \\
\text { Assunçio }\end{array}$ & 9 & $2007-2015$ & 7 & 2 & 20 & 2,2 & 15 & 1,7 & 10 & 10 & 0 & $\begin{array}{l}\text { Vandedei } 0 . \\
\text { Fenteita }\end{array}$ & 3 & $\begin{array}{l}\text { Jolo D. Lima, Zilda F } \\
\text { Mariene }\end{array}$ & 2 & $\operatorname{Sin}(1)$ \\
\hline 36 & William R. Fersera & 21 & $2006-2018$ & 13 & 3 & 55 & 2,8 & 30 & 1,4 & 29 & 20 & 0 & Deatnin R. Soures & $\mathrm{H}$ & Adelson R. Mesquin & 5 & $\sin (\theta)$ \\
\hline & Tatal & 473 & & 311 & 162 & 1273 & 2,7 & 753 & 1,6 & 632 & 636 & 5 & & & & & \\
\hline
\end{tabular}

Fonte: dados da pesquisa.

* SI (Sem informações). Cinco trabalhos não constam informações sobre membros de banca.

${ }^{1}$ A coluna "Parcerias" se refere à quantidade total de parcerias realizadas pelo orientador.

2 A coluna "Parceiros" se refere à quantidade total de parceiros individuais.

${ }^{3}$ A coluna "Repetição de banca" indica se ocorreu repetição de todos os membros da banca no que se refere à quantidade de repetições entre parênteses.

Os campos alimentados com hífen indicam que o orientador realizou mais de uma banca de defesa, porém nem um membro de banca ou instituição registrou participação acima de uma vez.

A Universidade Federal de Goiás (UFG) se destacou na quantidade de parcerias (15 de 36). Beatriz Ribeiro Soares foi a docente interna (UFU) e João Donizete Lima o examinador 
externo que mais se sobressaíram no volume de colaborações individuais: 7 (19\%) e 4 (11\%), respectivamente.

Apenas 10 orientadores formaram bancas com os mesmos membros (repetição de banca), sendo 8 ocorrências desse tipo repetidas uma vez. Esse fato demonstra a característica abrangente de se diversificar essas seleções. É importante destacar que 26 (72\%) orientadores não participaram mais de uma vez em comissão avaliativa composta pelos mesmos integrantes. O Grafo 1 ilustra as conexões observadas na coleta de dados.

Grafo 1 - Rede de colaboração entre membros de bancas examinadoras do PPGeo/UFU

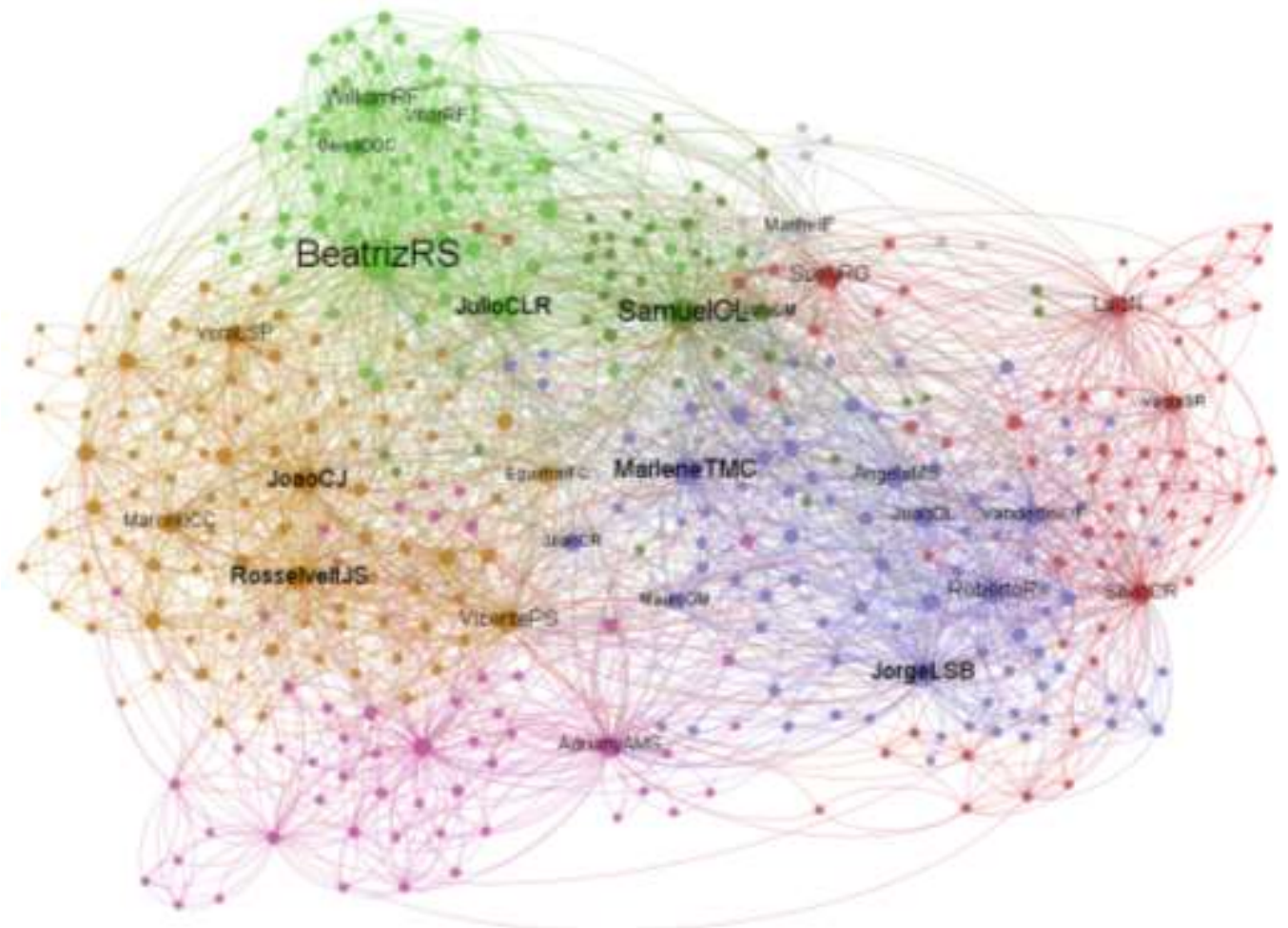

Fonte: dados da pesquisa.

Como recurso para a geração do Grafo 1, atribuiu-se a função de modularidade, a partir da qual foram identificados e rotulados 6 grupos de maior interação com os mesmos nós. Os destaques são os orientadores que lideram em número de links (parcerias), sendo Beatriz R. Soares, com 116 links; Samuel C. Lima, 95; Rosselvelt J. Santos, 87. Essas informações indicam ampla variação de examinadores, além de baixa ocorrência de repetições de bancas. 


\section{Formação acadêmica e temática dos orientadores e dos membros das bancas}

Para responder a pergunta norteadora desta pesquisa, a saber: "Como que se estruturam as redes de colaboração de bancas examinadoras em um programa de pós-graduação?”, adotouse a estratégia de consulta aos currículos, dissertações e teses produzidas pelos 36 orientadores e 390 membros de bancas, dentre as 1.273 parcerias firmadas entre 2000 e 2018 . A fim de entender o objeto de pesquisa aqui delimitado, foram coletados dados referentes à formação acadêmica (graduação, mestrado e/ou doutorado) desses componentes; tais informações, essenciais para compreender o objeto desta pesquisa, estão compiladas na Tabela 2.

Com base no levantamento, convém ressaltar as 3 instituições que mais figuraram na trajetória de formação dos orientadores do PPGeo/UFU: Universidade de São Paulo (USP), Universidade Estadual Paulista (Unesp) e Universidade Federal de Uberlândia (UFU), em 33, 21 e 20 ocasiões respectivamente, representando $70 \%$ das 106 instituições. É importante informar que o professor Túlio Barbosa possui dois títulos de doutorado, porém considerou-se apenas um deles, em Geografia.

Tabela 2 - Formação acadêmica e núcleo formador dos orientadores do PPGeo/UFU

\begin{tabular}{|c|c|c|c|c|c|c|c|c|c|c|}
\hline & Orisutadar & $\begin{array}{l}\text { Inatiraicia } \\
\text { Crnduario }\end{array}$ & $\begin{array}{l}\text { Graduagale } \\
\text { Ceveratias }\end{array}$ & $\begin{array}{l}\text { Orientadar } \\
\text { Greduagde }\end{array}$ & $\begin{array}{l}\text { Tentiruiaio } \\
\text { Mentrade }\end{array}$ & $\begin{array}{l}\text { Mentirade } \\
\text { Geoprafia }\end{array}$ & Orisasalar Mlestrade & $\begin{array}{l}\text { Instituizas } \\
\text { Deutarade }\end{array}$ & $\begin{array}{l}\text { Doutarado } \\
\text { Geversatia }\end{array}$ & Oriestader Dsusarade \\
\hline I & Ahing A. M Sertyiv & LFU & $8 i=$ & II & tTU & $\sin$ & Virma R. Fich & $t m$ & $\sin$ & Fule M L . Mesea \\
\hline 2 & Anterio \& Rithers & UIP & $\operatorname{Sin}$ & II & $\operatorname{tap}$ & Iim & Carlew A. F Menteity & tarF. & $\operatorname{lin}$ & Aagento Hi v. Thardil \\
\hline 3 & Deatns R. Soever & toro & $\mathrm{i}=$ & it & verp & $\sin$ & Mria A C G Lembet & tre & $\mathrm{I}=$ & Mria A E Lamos \\
\hline 4 & Catber of Breabse & pue & she & sit & 1208 & sae & Rotele C. Oaver & $t \geq$ & 150 & Dout 1 Startine \\
\hline 5 & Clasuet A D. Bascers & LSP & Iin & II & tSP & $\sin$ & $\alpha_{\beta} C_{n e n}$ & $\operatorname{ta}$ & tien & Op Cran \\
\hline 6 & Denuen I Fertira & LFAM & Lins & Yera Xt P Misonum & thas & Wae & Rieardo L. Farvet. & $\mathrm{LA}$ & Sin & Crudent B hapenas \\
\hline 7 & Doefta C. Iartea & DSD & $\operatorname{Sin}$ & Fotitherte Conalthere & $\mathrm{t} 99$ & $\lim$ & Paciuburto Cavathere & $L \$$ & lien & Fuliberts Crazhevere \\
\hline 8 & Geina D Q Clept & TEM & lim & II & tomes & $\lim$ & Aàrasu Maria Pantasti & TAESP & Sin & Poeapeo F. Curvatue \\
\hline 9. & 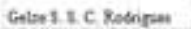 & LSTP & Sim & III & 199 & $\sin$ & 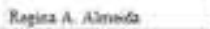 & $\operatorname{tr}$ & Lien & Marimen T M. Celerasti \\
\hline 16 & labe Claper Xnier & GNen & Shen & If & LNED & $\lim$ & Bitris C. Baxy & LNES & Sien & VeraM H M Conta \\
\hline II & $\operatorname{lesp}$ I 1. Bete & LFy & 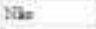 & in & DWE & sace & Jeral 14 lastos & tws & Sin & Rentaso Berz \\
\hline 12 & Jalia C.L. Ramits & tFR & Iin & II & पFN & $\lim$ & Roberto L. Coctia & $\operatorname{tag}$ & Sin & Ansila I O. Lemea \\
\hline 13 & Inir A Otinein & tFU & lint & II & tom & Iim & Jeni E. O Campes & $\ln a$ & $\operatorname{Sin}$ & Jan E Q Cumper \\
\hline \multirow{2}{*}{41} & Init Ninhyeat & TDESF & Käs & II & $\operatorname{vap}$ & $\Delta \mathrm{z}$ & L lewo V Zogsetis & ves & Nase & Litare V Zeqoetis \\
\hline & & Deiventi & & & Vhiturentit & & & Veivenec & & \\
\hline 15 & Mantives Fetr & Lat & N3s: & P & af Atlerta & $\mathrm{X}_{\mathrm{X} e}$ & Grant Fisuer & Lanal & Naso & Locure Cortier \\
\hline 16 & Mertele C. Chislats & LFM & Iin & Meit Besei & thas & lim & Rouarpula A \& Henpmitot & LFU & Sim & Yoral. I Pouts \\
\hline 17 & Maria B I. Bernuder & LFU & Iin & II & पFU & Im & Tina R. P. Such & tro & lim & Marless T.M. Coletansi \\
\hline is & Malese T M Colenari & FFCLSM & Sàz & II & tNese & $\lim$ & Livia de Oltreina & TARESE & $\mathrm{sin}=$ & Liviz de Olinvin \\
\hline 19 & Merie F. V. Perin & toness & $\sin$ & Inein P. Kulil & torese & $\operatorname{Sirs}$ & Satain P. Xats] & VSEBP & $\sin$ & Samin P. Kahl \\
\hline 20 & Pablo C, Stendel & uro & Sint & Artorte o Ribure & tro & $\operatorname{sim}$ & Altueso o Rilest & uro & $\operatorname{Sin}$ & Aarred C. Lima \\
\hline 21 & Pache I I Perander & tro & sai & gt & tro & N30 & Rafatc sila & unv & Iite & 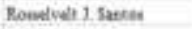 \\
\hline 22 & Rita C. M Sous & $\mathrm{n}$ & u & II & thes? & $\sin$ & Silvie C. Bay & Whese & $\operatorname{Iin}$ & Shaje C Bray \\
\hline 2) & Koberso Rous & uram & Sien & st & DOPE & sao & Enos M L L M Nere & $\mathrm{tw}$ & the & Mapto A. Lombardo \\
\hline 24 & 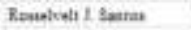 & ENIrUt & line & Belena C Catai & USP & Lim & Odente C. L Seabra & L\$ & lien & Othent C. L Jealn \\
\hline 25 & farras C Lims & tor & Sin & II & & Sase & Etinen D Bident & $\operatorname{ts}$ & Sim & law D. Qraiton Xiato \\
\hline 26 & Ithia C Rodripan & tSP & lim & II & & a & if & $\cos$ & Sin & brante $L I \operatorname{Ben}$ \\
\hline 27 & Gouly 2 . Granir & FAPICA & $\sin$ & II & USP & $8 \mathrm{sm}$ & Aflisen A Abres & tof & $\sin$ & Atlien d, Atroo \\
\hline \multirow[t]{2}{*}{2} & Tate batsou & woess & sea & It & toreir & $\mathrm{mm}$ & Elses a spoine & verear & $t=$ & soae o, $R$ Jouns \\
\hline & & & Iits & & & $8 \mathrm{~m}$ & & tro & $\operatorname{Iin}$ & Pacle R. Alneida \\
\hline 36 & Vacturiti o. Forrem & unic & Sin & Carlan MC Ramero & that & $\operatorname{sim}$ & detores G Ritevin & Inve & Sien & Atsoos laadi \\
\hline 30 & Vatia R. F. Vlact: & $\operatorname{tr}$ & 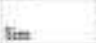 & II & $\operatorname{VPr}$ & Iim & Mreoelf F. G Ieutra & $\begin{array}{l}\text { Linivanas } \\
\text { Paria B }\end{array}$ & Thas & Yren L veontt \\
\hline 31. & Vatia I Bovelen & TNESF & $\sin$ & 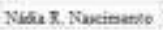 & usp & sae & A Belphe I Melf & tor & $\mathrm{Sag}$ & Asolyte I Melti \\
\hline 52 & Vena I. S Poode & FArt & $\sin$ & st & UNear & $\sin$ & Mignt C. faneas & torese & $\operatorname{Iim}$ & Mignel C. Sundes: \\
\hline "3 & Virmite P, slus & $t \pi$ & Iin & st & tsp & Im & Matia \& C.T sade & tmo & Iim & AtaMLDar \\
\hline 34 & Witer kiberiog filito & urt & Iin & st & the & sim & Rosinta L Coecita & L7ne & Sien & Roterto L Coenda \\
\hline 35 & Wrahiegroe L Aantriph & LTu & Sie & It & ure & $\mathrm{San}$ & Rogiea C: I Petran & UNES? & Sine & Actonio o Rloir \\
\hline 36 & wilkam in fetrin & tru & $\sin$ & Denin L. Perrina & tos & Siac & 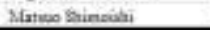 & 138 & $\operatorname{Sit}=$ & Andiat I G Lemes \\
\hline
\end{tabular}

Fonte: os autores.

SI = Sem informação. 
Dos 36 orientadores, apenas dois, Carlos R. Brandão e Manfred Fehr, não possuem formação em Geografia em qualquer nível de escolaridade, dessa forma, 94\% são da área. A relação entre orientadores e membros de bancas por área do conhecimento afim figura em número dominante: dos 1.273 componentes analisados, 1.059 (83\%) possuem alguma diplomação no segmento.

Observa-se a negligência quanto à normalização dos trabalhos, devido à considerável ausência de dados de membros de banca — inclusive, não foi encontrada menção de banca de graduação, por exemplo.

\section{Relações estabelecidas durante o período de formação dos orientadores e examinadores}

Para identificar as relações estabelecidas durante o período de formação dos orientadores e examinadores, analisaram-se as seguintes variáveis: instituição formadora; diplomação acadêmica em Geografia ou em outras áreas, considerando qualquer nível; orientadores e membros de banca de defesa de seus trabalhos. A relação destes últimos é aqui designada como núcleo formador, ou seja, aqueles que participaram da formação do orientador e dos membros de bancas. A Tabela 3 caracteriza a organização de bancas do PPGeo/UFU a partir dos resultados obtidos.

Conforme o levantamento realizado, a maioria dos orientadores (22) possui associação institucional $^{9}$, entretanto, o volume desses vínculos é baixo: 52 , o que representa $4 \%$ do total de parcerias, 1.273. Tal fato demostra que o PPGeo/UFU não organiza essas participações por meio do critério da relação estabelecida durante a formação dos orientadores e convidados.

Observou-se também que $7(19,4 \%)$ orientadores convidaram agentes de seu núcleo formador em 25 ocasiões (média de 2\%). Portanto, tal volume indica que esse tipo de conduta não é regular nos processos do PPGeo/UFU. Além disso, não se constatou um grande conjunto de parcerias estimuladas por meio da relação entre membros do núcleo formador de orientadores enquanto participante da trajetória acadêmica dos integrantes de banca: foram 13 orientadores $(3,46 \%)$ em 44 participações.

\footnotetext{
${ }^{9}$ Ocorre quando a universidade formadora desses profissionais é a mesma dos examinadores.
} 
Por último, verificou-se a ocorrência de participações de orientadores no núcleo formador dos membros de banca, cujo resultado reflete equilíbrio numérico (21). Vale destacar, contudo, que tal situação figurou em atividades de 69 examinadores (16,2\% de 426 docentes) em 101 oportunidades ( $8 \%$ do total de 1.273 participações). Dessa forma, é possível constatar o fato de esse tipo de associação não ser representativa.

Tabela 3 - Relações estabelecidas durante a formação dos orientadores e examinadores

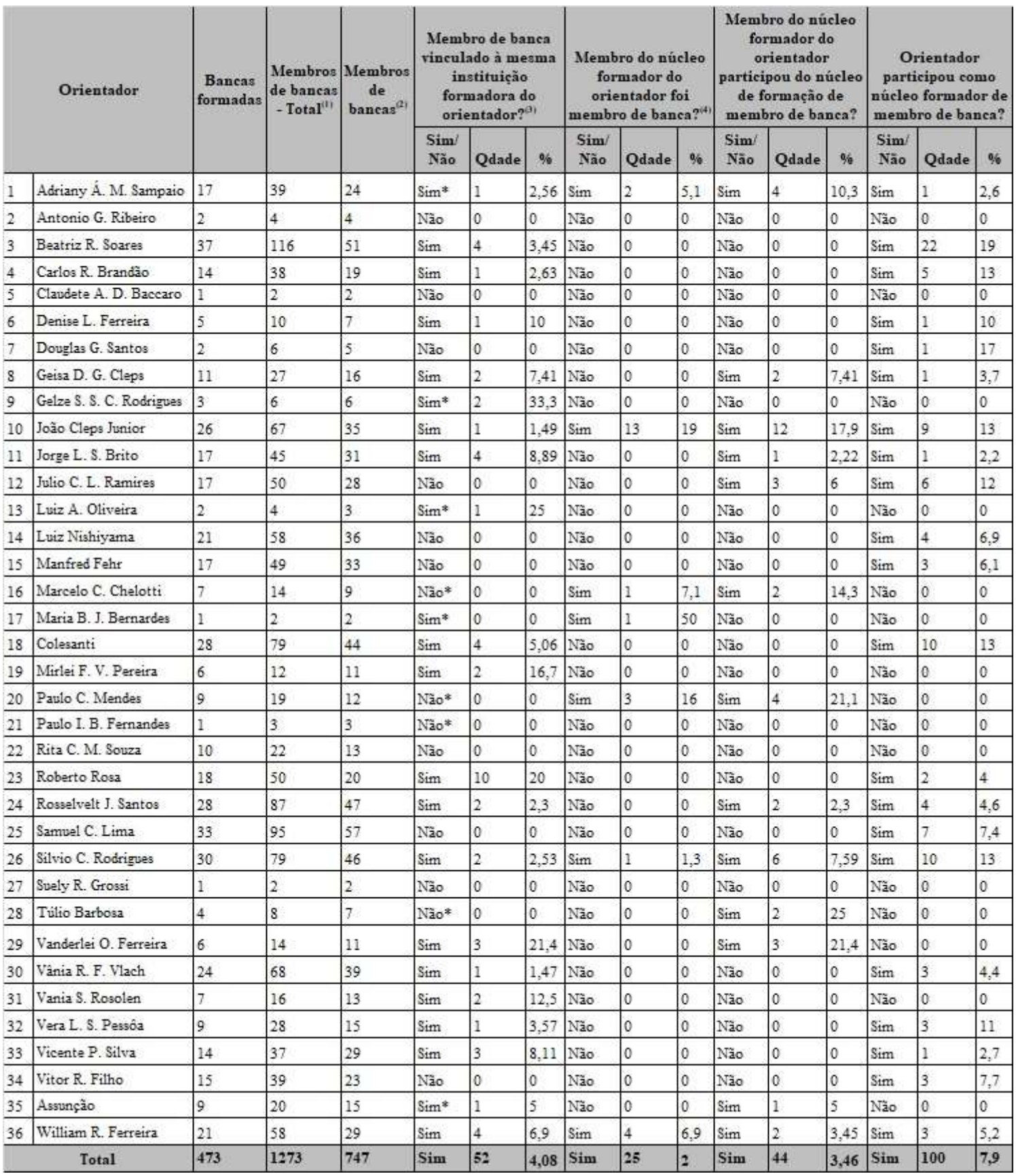

Fonte: dados da pesquisa.

${ }^{1} \mathrm{Em}$ "Membros de banca - total", foram apontadas todas as parcerias, incluindo repetições de participação.

${ }^{2} \mathrm{Em}$ "Membros de banca", optou-se por examinadores que participaram em processos de maneira individual. 
${ }^{3}$ Em "Membros de banca vinculados à instituição formadora do orientador", não foi considerada a UFU, pois esta é uma relação intrainstitucional. Informou-se a quantidade de vezes que um parceiro atuou como membro de banca, incluindo as repetições. Consideraram-se, ainda, todas as instituições formadoras citadas em currículo.

${ }^{4}$ São categorizados como integrantes do núcleo formador os docentes que orientaram ou participaram de bancas de defesas de mestrado e/ou doutorado dos orientadores.

A coluna "Qdade", de quantidade, refere-se ao número de oportunidades em que determinada situação ocorreu. Todas as porcentagens foram calculadas sobre o valor de "Membros de banca - total".

\section{Proximidade geográfica institucional dos membros das bancas}

No que diz respeito à quantidade geral de parcerias registradas, identificaram-se 1.269 examinadores com vínculos institucionais, sendo 633 do tipo intrainstitucionais e 636 interinstitucionais. Isso indica 90 organizações diferentes de colaboração no programa. As afiliações institucionais dos membros das bancas examinadoras do PPGeo/UFU, bem como o total de participações em bancas examinadoras são apresentadas na Tabela 4.

Tabela 4 - Afiliações institucionais dos membros das bancas examinadoras do PPGeo/UFU

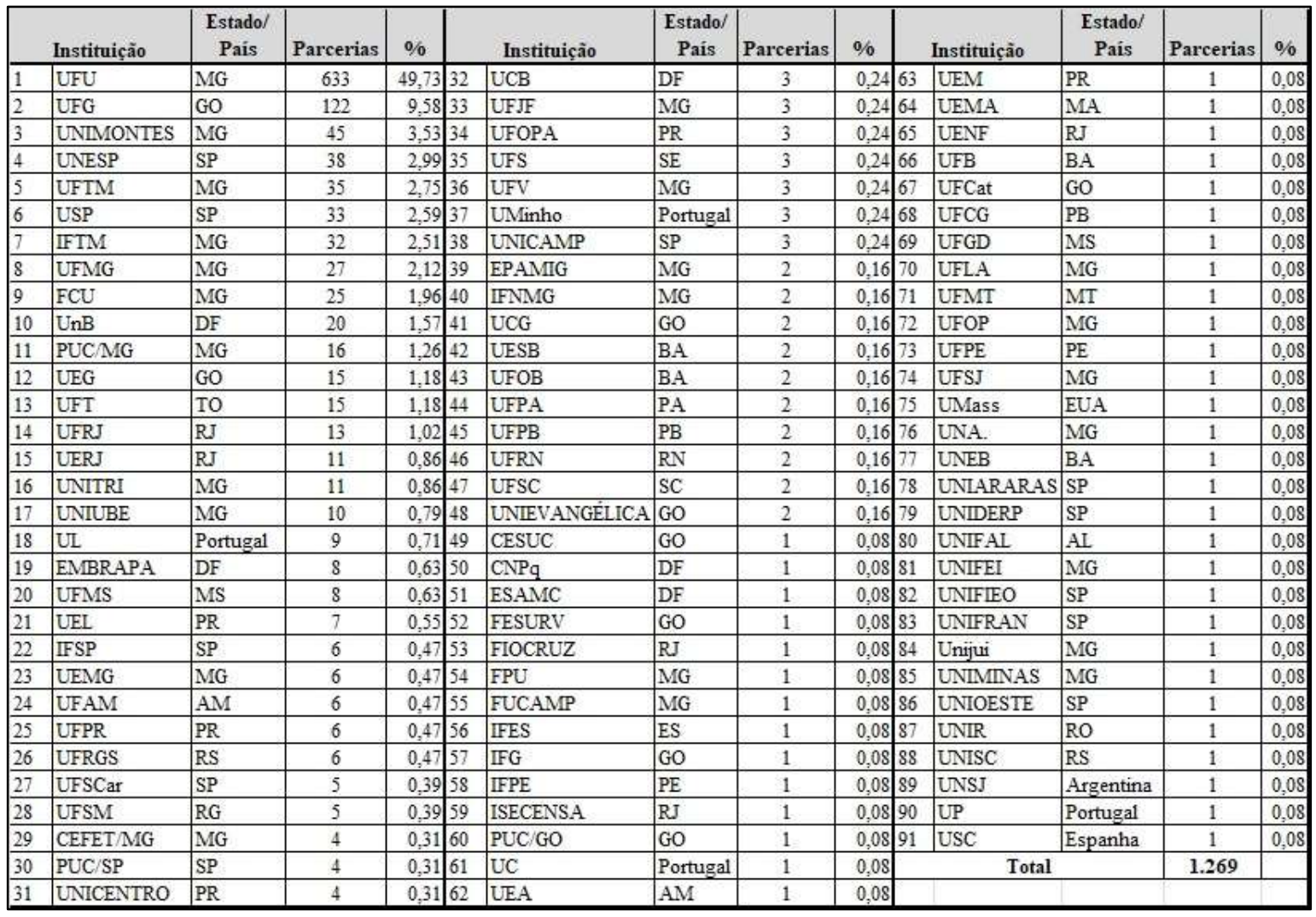

Fonte: dados da pesquisa.

$\%$ = porcentagem em relação ao total de participações (1.273). O número 1.269 se refere à somatória do total de afiliações identificadas.

Diante dos dados obtidos, a Universidade Federal de Goiás (UFG) se sobressai como instituição de maior número de parcerias (122), representando 19\% das colaborações externas e aproximadamente $10 \%$ do volume total (1.273). Por sua vez, as bancas do programa 
registraram 16 participações (3\%) de examinadores vinculados a 6 instituições internacionais, sendo Portugal o país com o maior número acumulado.

Notam-se também 633 ocorrências de membros de bancas afiliados à UFU, embora nem todos estivessem vinculados ao Instituto de Geografia, pertencendo, portanto, a outras unidades acadêmicas. Essa elevada ocorrência é natural, visto que a presença de orientadores e de professores nas avaliações é obrigatória. Enfatiza-se o fato de 39 instituições terem sido representadas em apenas uma ocasião ( $43 \%$ do total de 90 ), indicativo de que não havia concentração institucional de parceiros.

O Grafo 2 ilustra a rede de colaboração interinstitucional formada pelo PPGeo/UFU, sendo as instituições simbolizadas por pontos e suas relações, por arestas. Nesse sentido, quando algum docente externo fez parte de uma banca do programa, cria-se automaticamente uma associação com as instituições dos demais avaliadores.

Grafo 2 - Rede de colaboração interinstitucional formada pelas bancas no PPGeo/UFU

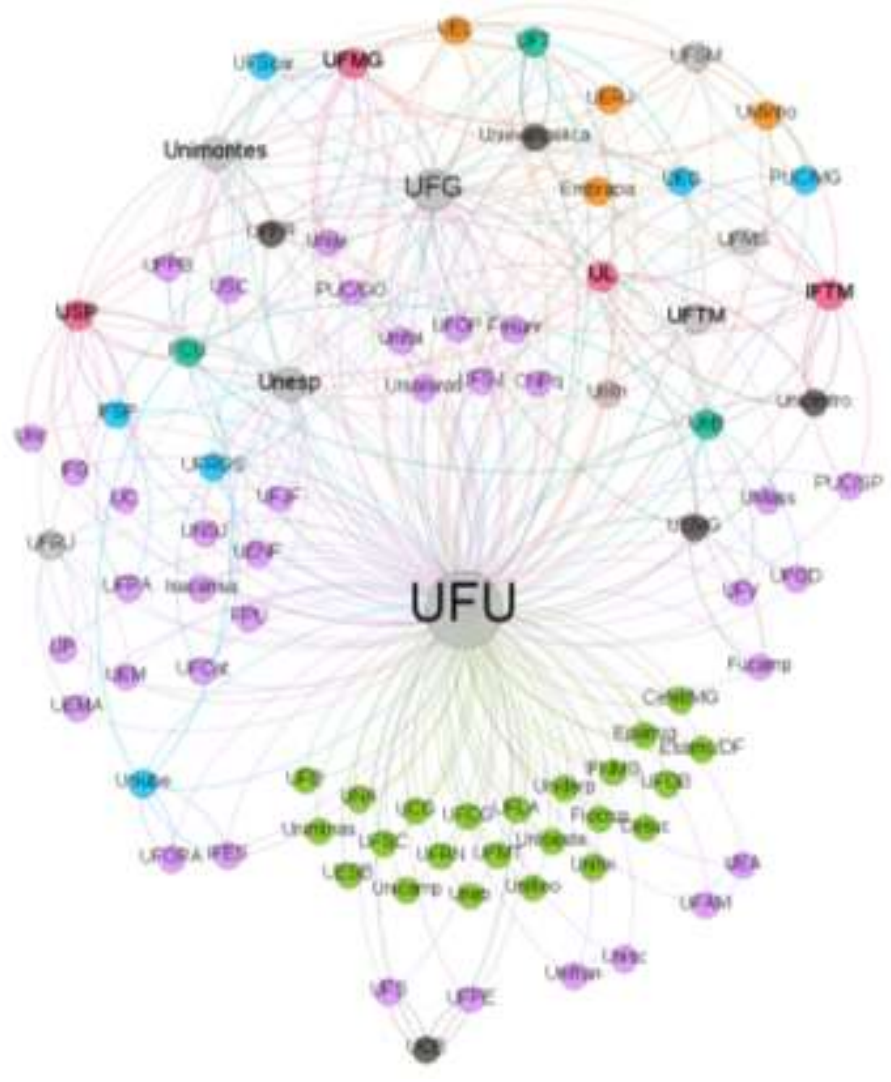

Fonte: dados da pesquisa.

As demais instituições analisadas aparecem de maneira conectada à UFU, logo, essa universidade figura como ponto central em tais relações. Assim, as maiores densidades da rede são formadas entre parcerias externas com a UFG, 122 (9,58\%); Unimontes, 45 (3,53\%); 
Unesp, 38 (2,99\%); UFTM, 35 (2,75\%); USP, 33 (2,59\%). Esses indicadores demonstram que existe uma preocupação com a busca por diferentes instituições para a formação das bancas do programa, embora algumas delas apareçam com mais frequência.

Quanto à localização geográfica das instituições dos participantes das bancas, bem como o número de colaborações, identificaram-se as principais ocorrências de membros, considerando estados e regiões de afiliação. Os estados mais registrados, conforme as 636 participações interinstitucionais ${ }^{10}$ e instituições, respectivamente, foram: Minas Gerais, 230 $(35,16 \%)$ e 23; Goiás, 147 (23,11\%) e 10; São Paulo, 94 (14,78\%) e 11. Destacam-se ainda 33 participações do Distrito Federal e 27 do Rio de Janeiro, ambos com 5 instituições participantes. Dessa forma, é possível afirmar que a rede interinstitucional de bancas examinadoras do PPGeo/UFU possui característica estadual e regional.

No que se refere às parcerias firmadas pela UFU, foram encontradas instituições nas 5 regiões nacionais ${ }^{11}$. O Sudeste dominou em termos de influência, ao exibir 40 instituições e 352 parcerias, sem considerar a UFU; o Centro-Oeste aparece em seguida, com 17 instituições e 189 parcerias. Tal fato reafirma o perfil estadual e regional da rede interinstitucional de bancas examinadoras do programa.

Ainda nesse âmbito, foram estabelecidos vínculos com pesquisadores de 22 de 26 estados e Distrito Federal, o que demonstra abrangência relevante de 81\%. Apenas 5 estados não foram mencionados na base de dados analisada: Acre, Amapá, Ceará, Piauí e Roraima.

A participação de examinadores de instituições do Norte de Minas Gerais, como é o caso do Instituto Federal do Norte de Minas (IFNMG) (2) e, de maneira destacada, a Unimontes (32), explica-se por haver acordos entre o PPGeo/UFU com universidades situadas na cidade de Montes Claros. Dentre eles, é possível citar parcerias com as Faculdades Integradas do Norte de Minas (Funorte) nos anos 1990, onde era ofertado o curso de Mestrado Interinstitucional (Minter), e com a Universidade Estadual de Montes Claros (Unimontes), que disponibilizava o Doutorado Interinstitucional (Dinter) nos anos 2000. Esses projetos estreitam o contato entre membros das instituições envolvidas, aumentando o interesse em trabalhos compartilhados.

\footnotetext{
${ }^{10}$ Nos cálculos, foram consideradas apenas participações externas à UFU, a fim de se avaliar o grau de parceria.

${ }^{11}$ Centro-Oeste, Nordeste, Norte, Sudeste e Sul
} 


\section{Considerações finais}

Os dados levantados e analisados refletem a motivação para a composição em bancas examinadoras de defesas de mestrado e doutorado do PPGeo/UFU. A análise se deu em consideração a três principais hipóteses: investigou-se se sua constituição é motivada por proximidade geográfica; relações entre orientador e orientado; relações estabelecidas durante a formação dos membros, bem como relações temáticas. Dentre as hipóteses, foi constatado que as principais motivações se referem a temáticas/especialidades dos avaliadores, sendo a formação em Geografia observada na maioria dos currículos (81\%).

A proximidade geográfica das instituições parceiras também figurou como fator importante nessas atividades. Sendo assim, a maioria das universidades pertencia aos estados de Minas Gerais, Goiás e São Paulo, o que totaliza em 44 instituições $(48,9 \%)$ e 471 participações $(74 \%)$.

Além disso, é possível notar que a participação dos envolvidos nesses contextos não é um fator preponderante em relação à formação da rede colaborativa aqui de interesse. Afinal, apenas $12 \%$ do total levantado exibiram ligações nas quais os membros do núcleo formador do orientador participaram do núcleo de trajetória acadêmica dos membros de banca. A ocorrência de parcerias de orientadores no núcleo formador dos 426 membros de banca equivale a 16,2\% e $8 \%$, respectivamente, do total de 1.273 ocorrências. Vale ressaltar que o membro do núcleo formador se refere aos docentes que orientaram trabalhos e/ou participaram de bancas de defesa dos envolvidos, orientadores e membros de bancas. Dessa forma, esse tipo de associação, tais como relações entre orientadores e orientandos, não se mostrou tão expressivo.

A colaboração estabelecida com avaliadores de instituições nacionais e internacionais desencadeia uma relevante rede entre docentes e pesquisadores. Isso possibilita o descobrimento de novas abordagens e pesquisas, assim como amplia o fortalecimento e certificação de estudos em curso. As 1.273 parcerias realizadas pelas bancas do PPGeo/UFU, dentre as quais há 636 do tipo externa, abrangem 22 estados brasileiros e 6 instituições internacionais de 4 países diferentes. Logo, a amplitude de suas conexões firmadas é legitimada por esses números. Destaca-se, também nesse aspecto, a consolidação da colaboração entre representantes das instituições parceiras ou projetos afins da UFU ou do programa, proporcionando estudos em regiões ainda não exploradas, como o Norte de Minas Gerais. 
Em adição à proximidade geográfica das bancas, constatou-se que a rede interinstitucional de bancas examinadoras do PPGeo/UFU é de característica estadual, pois Minas Gerais é o estado com o maior número de universidades com membros de bancas (23), através de $230(35,16 \%)$ das parcerias. Além disso, o número de participação de membros de estados limítrofes também é bastante expressivo: Goiás, 147 (23,11\%) e 10; São Paulo, 94 $(14,78 \%)$ e 11 , respectivamente. Esse conjunto de dados confirma a hipótese de que a composição das bancas é fortemente influenciada por proximidade geográfica entre as instituições e seus membros.

Diante disso, a rede de colaboração analisada tem característica esparsa, não exprimindo forte relação com a instituição formadora dos orientadores do programa e examinadores. Do ponto de vista temático, as colaborações apresentam certa densidade dentro da Geografia. Também, ao reunir especialistas lotados naquele estado, comprova-se que a especialidade do membro é um fator decisivo para a composição nessas etapas de avaliação, sendo mais importante que as relações interpessoais estabelecidas durante o processo de orientação e formação dos orientadores (antigo orientador e ex-orientandos, por exemplo).

Todo o contexto até aqui retratado buscou destacar a importância das bancas examinadoras e a função determinante de seus membros para com a homologação de trabalhos que demandaram tempo e dedicação de orientandos e orientadores. Fatores que respaldam o estudo do tema, sendo cabíveis novas pesquisas com esse viés em dissertações e teses. Notadamente, as normas da UFU e do PPGeo podem interferir nos resultados, pois regulam comportamentos humanos, não sendo possível extrapolar de maneira descontextualizada os resultados de todos os programas de pós-graduação brasileiros. 


\section{Referências}

BALANCIERI, R. Análise de redes de pesquisa em uma plataforma de gestão em ciência e tecnologia: uma aplicação à Plataforma Lattes. 2004. Dissertação (Mestrado) Universidade Federal de Santa Catarina, 2004. Disponível em: https://repositorio.ufsc.br/xmlui/bitstream/handle/123456789/87468/224645.pdf?sequence=1 \&isAllowed=y. Acesso em: 5 jun. 2020.

BRASIL. Coordenação de Aperfeiçoamento de Pessoal de Nível Superior. Documento de área: área 36: geografia. Brasília, DF: CAPES, 2016. Disponível em:

https://capes.gov.br/images/documentos/Documentos_de_area_2017/36_geog_docarea_2016. pdf. Acesso em: 12 abr. 2020.

BRASIL. Ministério da Educação. Resolução no 7, de 11 de dezembro de 2017. Estabelece normas para o funcionamento de cursos de pós-graduação stricto sensu. Brasília, DF, 2017. Disponível em: http://portal.mec.gov.br/docman/dezembro-2017-pdf/78281-rces007-17pdf/file. Acesso em: 27 maio 2020.

COSTA, L. et al. (coord.). Redes: uma introdução às dinâmicas da conectividade e da autoorganização. Brasília: WWF Brasil, 2003. Disponível em: http://www.dominiopublico.gov.br/download/texto/et000023.pdf. Acesso em: 30 maio 2020.

DANUELLO; J. C; OLIVERIA, E. F. T. Análise cientométrica: produção científica e redes colaborativas a partir das publicações dos docentes dos programas de pós-graduação em Fonoaudiologia no Brasil. Em Questão, Porto Alegre, v. 18, p. 65-79, dez. 2012. Disponível em: https://seer.ufrgs.br/EmQuestao/article/view/33178. Acesso em: 2 out. 2020.

DIAS, L. C. Redes: emergência e organização. In: CASTRO. E. I.; GOMES, P. C. C.; CORREAA, R. (org.). Geografia: conceitos e temas. 2. ed. Rio de Janeiro: Bertrand Brasil, 2000. p. 141-162.

KILEY, M. 'You don't want a smart Alec': selecting examiners to assess doctoral dissertations. Studies in Higher Education, [s. l.], v. 34, n. 8, p. 889-903, Dec. 2009. DOI: https://doi.org/10.1080/03075070802713112. Disponível em: https://srhe.tandfonline.com/doi/full/10.1080/03075070802713112?casa token=wskvS44UaQAAAAA\%3AYfhIMM6Y4w7KuOEcIKd3UjbQj4DwuNktaZD22orzWrP955sPKaa1H756 SWbUt9sry3iUqPwsBvQ\#.Xr2vK2hKg2w. Acesso em: 27 maio 2020.

MACIAS-CHAPULA, C. A. O papel da informetria e da cienciometria e sua perspectiva nacional e internacional. Ciência da Informação, Brasília, v. 27, n. 2, p. 134-140, maio/ago. 1998. Disponível em: http://www.scielo.br/scielo.php?pid=S010019651998000200005\&script=sci_abstract\&tlng=pt. Acesso em: 20 abr. 2020.

OLIVEIRA, E. F. T. Estudos métricos da informação no Brasil: indicadores de produção, colaboração, impacto e visibilidade. Marília: Oficina Universitária, 2018. Disponível em: https://www.marilia.Unesp.br/Home/Publicacoes/estudos-metricos-da-informacao-no-brasil--e-book.pdf. Acesso em: 20 abr. 2018. 
PEZZI, S.; STEIL, A. V. Análise do processo de exame de grau na pós-graduação stricto sensu. Educação e Pesquisa, São Paulo, v. 35, n. 1, p. 33-50, jan./abr. 2009. Disponível em: http://www.scielo.br/pdf/ep/v35n1/a03v35n1.pdf. Acesso em: 11 abr. 2020.

SALOMON, D. V. Como fazer uma monografia. 13. ed. São Paulo: Martins Fontes, 2014.

TELMO, F. A. Análise de redes sociais de colaboração em bancas de defesa de doutorado na Pós-Graduação em Ciência da Informação. 2019. Dissertação (Mestrado) -

Universidade Federal da Paraíba, João Pessoa, 2019. Disponível em:

https://repositorio.ufpb.br/jspui/bitstream/123456789/17150/1/Arquivototal.pdf. Acesso em: 6 jun. 2020.

TINKLER, P.; JACKSON, C. The doctoral examination: a handbook for students, examiners and supervisors. Bershire: McGraw-Hill Education, 2004. Disponível em: https://epdf.pub/the-doctoral-examination-process.html. Acesso em: 30 maio 2020.

TINKLER, P.; JACKSON, C. Examining the doctorate: institutional policy and the PhD examination process in Britain. Studies in Higher Education, [s. l.], v. 25, n. 2, 2000.

Disponível em: http://web-a-

ebscohost.ez34.periodicos.capes.gov.br/plink?key=10.83.10.81_8000_1115584035\&site=eho $\underline{\text { st } \& \text { scope }=s i t e ~} \& \mathrm{db}=a p h \& A N=3324413 \&$ msid $=603980735$. Acesso em: 30 maio 2020.

UNIVERSIDADE FEDERAL DE UBERLÂNDIA. Programa de Pós-Graduação em Geografia. Instrução Normativa - PPGEO No 01/2016. Estabelece critérios e procedimentos para composição de bancas examinadoras para dissertações de mestrado e teses de doutorado no programa de pós-graduação em Geografia PPGEO-UFU. Uberlândia, 2016. Disponível em:

http://www.ppgeo.ig.ufu.br/sites/ppgeo.ig.ufu.br/files/Anexos/Bookpage/IntrucaoNormativaP PGEO_Bancas-Dissert-Teses-2016.pdf. Acesso em: 12 abr. 2020. 